\title{
Surface Roughness of Milled Sheet Molding Compound Composites
}

\author{
A. UYSAL*, M. Altan \\ Yildiz Technical University, Department of Mechanical Engineering, 34349, Istanbul, Turkey
}

\begin{abstract}
Sheet molding compounds (SMC) are alternative materials in manufacturing of structural components, automotive components and electrical resistant parts, due to their high strength, light weight, easy formation and low material cost. However, machining is demanded as a secondary process for achieving the final shape of the part for assembly. During machining of SMC composites, some problems are faced because of the different machining characteristics of polymer matrix and fiber reinforcement. In this study, commercial SMC composite including 25 wt.\% polyester, $30 \mathrm{wt} . \%$ glass fiber and $45 \mathrm{wt} . \%$ calcium carbonate, was milled under different depth of cut, feed and cutting speed. Taguchi experimental design was used to determine the effectiveness of the parameters. After the slots were milled, the roughness of the machined surfaces was investigated and it was found that lower feed, higher depth of cut were more effective than cutting speed in decreasing surface roughness.
\end{abstract}

DOI: $10.12693 /$ APhysPolA.127.1218

PACS: 81.05.Qk

\section{Introduction}

Sheet molding compounds (SMC) are some of the members of the fiber reinforced family. It is the combination of glass fiber, polyester and calcium carbonate. This combination provides excellent properties such as light weight, high stiffness and easy formation. Because of this, they have become very popular in the fields where corrosion resistance is needed and also in applications of automotive components, high-strength electrical parts, business equipment cabinets, personal watercraft, and various structural components [1, 2].

SMC composites are manufactured in the shape of sheets by compression molds. Therefore, sheets always need a secondary process such as milling or drilling for obtaining the final shape of the part, before the assembly stage. However, fibers and polymer matrix bring some problems during machining. First of all, their machinability by conventional methods differs from that of metals $[3,4]$. When glass fiber reinforced polymers (GFRP) are machined, fibers are cut across or along their direction and they leave a deformed machined surface with high surface roughness [5]. On the other hand, matrix is ductile and it poorly tolerates the effect of the heat, generated during machining, which results in strong deformation of the material. In most of the studies, the cutting parameters, effecting surface roughness of fiber reinforced polymers, were feed rate and cutting speed. Secondly, depth of cut, type of tool material, and tool geometry were also investigated [6-8]. Spur and Wunsch [6] found that increasing feed rate increased surface roughness of machined GFRP, but there was no dependence on the cutting speed. On the contrary, Ramulu [7]

* corresponding author; e-mail: auysal@yildiz.edu.tr reported that high cutting speed improved surface quality. The effects of cutting parameters for SMC composites on tool wear were investigated during drilling, and they found that feed was significant in improving tool wear [9]. Uysal [10] investigated the effects of feed rate and drill point angle on the surface roughness of holes during drilling operation of SMC composites. Optimal surface roughness was observed when drill tools with small point angle and lower feed rates were used. Rajasekaran et al. [11] made an investigation on turning of polymer composites containing carbon fibers. They used Taguchi analysis and reported that surface roughness of the machined part had increased with increasing feed. On the other hand, they found that cutting speed was effective in the reduction of surface roughness as it was increased.

In this experimental study, researchers focused on the milling of SMC, which has not been studied scientifically during milling operation as much as other cutting processes. The effect of the cutting parameters on the roughness of the milled surfaces was investigated and Taguchi analysis was used in the experimental design.

\section{Experimental study}

\subsection{Materials and equipment}

Commercial sheet molding compound (SMC) which was used as composite material, was produced from 25 wt.\% polyester, $30 \mathrm{wt} . \%$ glass fiber $(25 \mathrm{~mm}$ in length, randomly chopped strand, average diameter of $0.05-$ $1 \mathrm{~mm})$ and 45 wt.\% calcium carbonate $\left(\mathrm{CaCO}_{3}\right)$. Compression molding was performed with an industrial hydraulic press (maximum force 250 tons). The press was equipped with a standard rectangular mold that could be used to produce $8 \mathrm{~mm}$ thick plates under compression pressure of $65 \mathrm{MPa}$ for 60 seconds in a mold heated to $150{ }^{\circ} \mathrm{C}$. The dimension of the plate was $180 \times 120 \mathrm{~mm}^{2}$. The mechanical properties of the material are given in 
Table I. Tungsten carbide (WC) end mills with four cutting blades were used in the experiments. End mill diameter was $8 \mathrm{~mm}$ and helical angle was $30^{\circ}$. SMC composite material parts were machined by First MCV-300 CNC Machining Center. This machine can perform at maximum of $8000 \mathrm{rpm}$ and at $10000 \mathrm{~mm} / \mathrm{min}$ feed rate. Arithmetic mean values of surface roughness $\left(R_{a}\right)$ of the machined slots were measured by Time TR 220 surface roughness device. Five measurements were done on each machined surface, along the feed direction and then the average of the measurements was calculated. The photographs of the machined slots were taken by a digital stereo microscope.

Mechanical properties of sheet molding

TABLE I compound (SMC) parts.

\begin{tabular}{c|c|c|c}
\hline \hline$E$ Module & $10 \mathrm{GPa}$ & Bending Strength & $115 \mathrm{MPa}$ \\
\hline Tensile Strength & $55 \mathrm{MPa}$ & Impact Resistance & $55 \mathrm{~kJ} / \mathrm{m}^{2}$ \\
\hline Bending Module & $9 \mathrm{GPa}$ & &
\end{tabular}

\subsection{Design of the experiments}

Determination of the optimum cutting parameters for minimum surface roughness was carried out by Taguchi method. Cutting speed, feed, and depth of cut were chosen as key factors. Three variable factors with three levels were studied as shown in Table II; therefore, the L9 orthogonal array (OA) was selected for this study. The layout of the L9 OA is given in Table III.

Variable factor levels.

TABLE II

\begin{tabular}{c|c|c|c}
\hline \hline Factors & Level 1 & Level 2 & Level 3 \\
\hline Cutting speed $(V), A[\mathrm{~m} / \mathrm{min}]$ & 75 & 100 & 125 \\
Feed $(s), B[\mathrm{~mm} / \mathrm{rev}]$ & 0.1 & 0.2 & 0.3 \\
Depth of cut $(a), C[\mathrm{~mm}]$ & 1 & 1.5 & 2
\end{tabular}

The layout of L9.

TABLE III

\begin{tabular}{c|c|c|c}
\hline \hline $\begin{array}{c}\text { Slot } \\
\text { number }\end{array}$ & $\begin{array}{c}\text { Cutting speed, } \\
A[\mathrm{~m} / \mathrm{min}]\end{array}$ & $\begin{array}{c}\text { Feed, } \\
B[\mathrm{~mm} / \mathrm{rev}]\end{array}$ & $\begin{array}{c}\text { Depth of cut, } \\
C[\mathrm{~mm}]\end{array}$ \\
\hline 1 & 1 & 1 & 1 \\
2 & 1 & 2 & 2 \\
3 & 1 & 3 & 3 \\
4 & 2 & 1 & 2 \\
5 & 2 & 2 & 3 \\
6 & 2 & 3 & 1 \\
7 & 3 & 1 & 3 \\
8 & 3 & 2 & 1 \\
9 & 3 & 3 & 2
\end{tabular}

The signal-to-noise ratios $(\mathrm{S} / \mathrm{N})$ for each experiment were determined by

$$
\mathrm{S} / \mathrm{N}=-10 \log \left[\frac{1}{n} \sum_{i=1}^{n} y_{i}^{2}\right],
$$

where $n$ is the number of surface roughness data sets (which is equal to 9 ) and $y_{i}$ is the surface roughness value for the $i$ th data set.

\section{Results and discussion}

\subsection{Influence of the process parameters on the surface roughness}

The relationship between the surface roughness and cutting parameters differs from the theories of metals, because the microstructure of glass fiber-reinforced composites is inhomogeneous and this causes deformations and fractures at micro level [11-13]. Besides, the generated heat levels are generally high enough to deform the polymer material, which results in surface roughness. Surface roughness results for the machined slots are given in Fig. 1a. According to Fig. 1a, surface roughness increases when the feed increases, due to the fact that fracture is harmless and more controllable and the strain rate is low at low feed. On the other hand, surface roughness decreases when cutting speed increases.
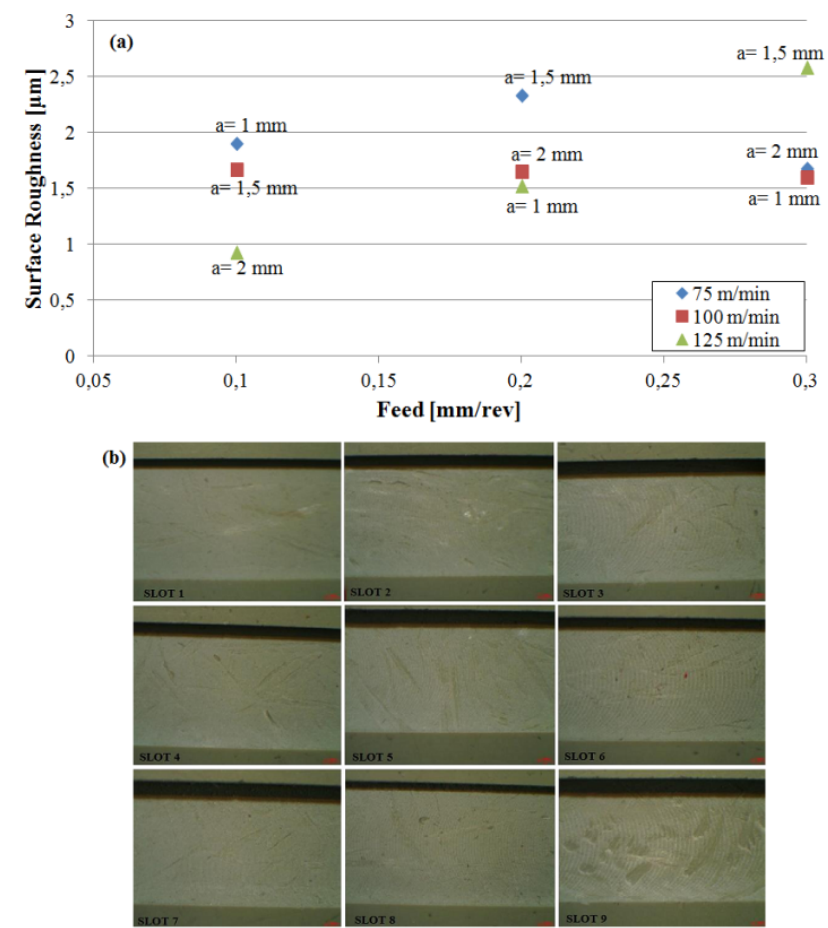

Fig. 1. (a) Surface roughness results for the machined slots, (b) photographs of machined slots (magnification $\times 7$ ).

In this study, lower feeds at constant depth of cut gave better surface quality due to less violent and more controllable fracture. At constant feed rate, as shown in Fig. 1a, small depth of cut was not advisable because during the cutting of composites, small depth of cut induces only partial removal of fibers from the matrix and this leads to a higher surface roughness [12]. On the contrary, this effect lost its significance at higher feed rates, which means depth of cut was more effective at lower feed rates. Cutting speed is known to be an effective parameter during cutting of fiber-reinforced composites and it is accepted, that high cutting speed values reduce surface roughness. Photographs of machined slots are given 
in Fig. 1b. The changes of the end mill marks with respect to machining parameters can be clearly seen. These marks have increased with the increase of feed and cutting speed. In addition, breaking of fibers, which is easyly seen in the photographs, affects negatively the surface roughness. The surface quality of slot 7 is better than that of the other slots and this situation is confirmed by the surface roughness values.

\subsection{Analysis of the results by Taguchi method}

The Taguchi method was applied to determine the optimal cutting parameters for minimal surface roughness. The highest difference value gives the parameter which influences the surface roughness the most. Such parameter is depth of cut, with corresponding difference value of 3.951 (Table IV). The measured surface roughness values and the signal-to-noise ratio results are given in Table $\mathrm{V}$. The optimal combination of process parameters was A3, B1, C3. Cutting speed had the lowest difference value of 2.085 which means it was the least effective factor. All these results obtained from Taguchi analysis are compatible with the discussion given in previous section, concerning Fig. 1b.

The response table of $\mathrm{S} / \mathrm{N}$ ratios.

TABLE IV

\begin{tabular}{c|c|c|c}
\hline \hline & $\begin{array}{c}\text { Cutting Speed, } \\
A[\mathrm{~m} / \mathrm{min}]\end{array}$ & $\begin{array}{c}\text { Feed, } \\
B[\mathrm{~mm} / \mathrm{rev}]\end{array}$ & $\begin{array}{c}\text { Depth of cut, } \\
C[\mathrm{~mm}]\end{array}$ \\
\hline Level 1 & -5.844 & -3.148 & -4.465 \\
Level 2 & -4.321 & -5.140 & -6.705 \\
Level 3 & -3.759 & -5.635 & -2.753 \\
Difference & 2.085 & 2.488 & 3.951
\end{tabular}

These results can be also observed from the $\mathrm{S} / \mathrm{N}$ ratio response diagrams drawn in Figure 2. The highest $\mathrm{S} / \mathrm{N}$ ratio for each factor gave the optimal process conditions, which correspond to the cutting speed of $125 \mathrm{~m} / \mathrm{min}$ $(A 3)$, the feed of $0.1 \mathrm{~mm} / \mathrm{rev}(B 1)$, the depth of cut of $2 \mathrm{~mm}(C 3)$. This set of data has been included in the design of experiment (slot 7) and the surface roughness is $0.9288 \mu \mathrm{m}$ that corresponds to the $\mathrm{S} / \mathrm{N}$ ratio of $0.6416 \mathrm{~dB}$ was obtained.

$\mathrm{S} / \mathrm{N}$ ratios for machined slots.

TABLE V

\begin{tabular}{c|c|c|c|c|c}
\hline \hline $\begin{array}{c}\text { Slot } \\
\text { nr. }\end{array}$ & $\begin{array}{c}\text { Cut. speed, } \\
A[\mathrm{~m} / \mathrm{min}]\end{array}$ & $\begin{array}{c}\text { Feed, } \\
B[\mathrm{~mm} / \mathrm{rev}]\end{array}$ & $\begin{array}{c}\text { Cut depth, } \\
C[\mathrm{~mm}]\end{array}$ & $\begin{array}{c}\text { Roughness } \\
{[\mu \mathrm{m}]}\end{array}$ & $\begin{array}{c}\mathrm{S} / \mathrm{N} \\
{[\mathrm{dB}]}\end{array}$ \\
\hline 1 & 75 & 0.1 & 1 & 1.9088 & -5.6152 \\
2 & 75 & 0.2 & 1.5 & 2.3406 & -7.3865 \\
3 & 75 & 0.3 & 2 & 1.6844 & -4.5289 \\
4 & 100 & 0.1 & 1.5 & 1.6730 & -4.4699 \\
5 & 100 & 0.2 & 2 & 1.6543 & -4.3723 \\
6 & 100 & 0.3 & 1 & 1.6070 & -4.1203 \\
7 & 125 & 0.1 & 2 & 0.9288 & 0.6416 \\
8 & 125 & 0.2 & 1 & 1.5242 & -3.6608 \\
9 & 125 & 0.3 & 1.5 & 2.5874 & -8.2573
\end{tabular}

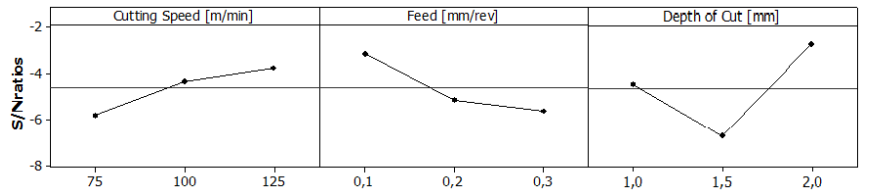

Fig. 2. $\mathrm{S} / \mathrm{N}$ ratios for cutting speed, feed rate and depth of cut.

\section{Conclusions}

In this study, effects of cutting parameters in milling of the sheet molding compound (SMC) composite materials were investigated. Cutting speed, feed, and depth of cut were chosen to be observed as key factors. The surface roughness was found to increase when the feed was increased and it was found to decrease when the cutting speed was increased. Higher depths of cut with lower feeds were more effective in decreasing surface roughness. When the photographs of machined slots were investigated, end mill marks and breaking of fibers were seen. These affected negatively the roughness of surface and more end mill marks occurred when feed and cutting speed were increased. Taguchi method was used to determine the optimal process conditions for minimum surface roughness and the result corresponds to the cutting speed of $125 \mathrm{~m} / \mathrm{min}(A 3)$, the feed of $0.1 \mathrm{~mm} / \mathrm{rev}$ $(B 1)$, the depth of cut of $2 \mathrm{~mm}(C 3)$.

\section{References}

[1] F.C. Campell, Structural Composite Materials, ASM International, Ohio, 2010.

[2] C.D. Raud, Composites for Automotive Applications, Rapra Technology, United Kingdom, 2000.

[3] J. Ramkumar, S. Aravindan, S.K. Malhotra, R. Krishnamoorthy, Int. J. Adv. Manuf. Tech. 23, 240 (2004).

[4] P.S. Sreejith, R. Krishnamoorthy, S.K. Malhotra, K. Narayanasamy, J. Mater. Process. Tech. 104, 53 (2000).

[5] G. Santhanakrishnan, R. Krishnamoorthy, S.K. Malhotra, J. Mech. Work. Technol. 17, 195 (1998).

[6] G. Spur, U.E. Wunsch, Manuf. Rev. 1(2), 124 (1988).

[7] M. Ramulu, D. Arola, K. Colligan, Engineering Systems Design and Analysis ASME 64(2), 93 (1994).

[8] J.P. Davim, F. Mata, Int. J. Adv. Manuf. Tech. 26(4), 319 (2005).

[9] A. Uysal, M. Altan, E. Altan, Int. J. Adv. Manuf. Tech. 58, 915 (2012).

[10] A. Uysal, Int. J. Arts. Sci. 3(1), 27 (2009).

[11] T. Rajasekaran, K. Palanikumar, S. Arunachalam, Procedia Eng. 51, 781 (2013).

[12] K. Palanikumar, Mater. and Design 28, 2611 (2007).

[13] E. Eriksen, Int. J. Mach. Tools Manuf. 39, 1611 (1999). 